\title{
Superação de dormência em sementes de Butia capitata
}

\author{
Overcoming dormancy in seeds of Butia capitata
}

\section{Claudimar Sidnei Fior ${ }^{\text {III }}$ Lia Rosane Rodrigues ${ }^{\mathrm{III}}$ Cristina Leonhardt $^{\mathrm{II}}$ Sergio Francisco Schwarz ${ }^{\mathrm{IV}}$}

\section{- NOTA -}

\section{RESUMO}

Com o objetivo de identificar métodos eficientes para a superação da dormência de sementes de B. capitata (Mart.) Becc. semeadas in vitro e em germinador, foram conduzidos testes com escarificação mecânica em présemeadura, através da abertura parcial ou total da cavidade embrionária de sementes isoladas dos endocarpos. A abertura da cavidade embrionária acelerou significativamente a germinação, principalmente quando houve retirada total do opérculo da semente, permitindo a germinação de, em média, 90\% dos embriões, independentemente da procedência dos acessos. A dormência das sementes de B. capitata parece estar relacionada com a barreira mecânica imposta pelos tecidos da semente que dificultam o desenvolvimento do embrião, o que sugere dormência exógena mecânica.

Palavras-chave: germinação, Arecaceae, cavidade embrionária.

\section{ABSTRACT}

Aiming to identify efficient conditions to break dormancy in Butia capitata (Mart.) Becc. seeds sown in vitro and in an incubator tests were conducted with mechanical scarification in pre-sowing, by partial or total opening of the seed embryonic cavity, isolated of the endocarps. The embryonic cavity opening accelerated germination significantly, especially when there was total removal of the seed cap, allowing germination on average $90 \%$ of embryos, regardless of the provenance of the accessions. The seed dormancy of $\boldsymbol{B}$. capitata seems to be related to the mechanical barrier imposed by the seed tissues that hamper the embryo development, suggesting mechanical exogenous dormancy.

Key words: germination, Arecaceae, embryonic cavity.
O butiazeiro [Butia capitata (Mart.) Becc. Arecaceae], palmeira característica do Uruguai e do Brasil, tem grande demanda para uso ornamental e agroindustrial, cujos frutos podem ser processados (TONIETTO et al., 2009). As fibras têm emprego artesanal e industrial, porém, tanto o emprego paisagístico quanto a constituição de pomares são limitados pela dificuldade de produção comercial de mudas, uma vez que a reprodução sexuada é atualmente a única forma de propagação, no entanto, é lenta e o percentual de germinação é baixo (GEYMONAT \& ROCHA, 2009).

A germinação de sementes de palmeiras é favorecida por tratamentos de pré-semeadura, como a imersão em água, para acelerar a embebição; a estratificação em temperaturas baixa ou alta; a escarificação e a retirada das sementes dos frutos para eliminação de um possível inibidor natural da germinação (ROBINSON, 2010). Em B. capitata, os resultados mais promissores obtidos até o presente momento (CARPENTER, 1988; SCHLINDWEIN et al., 2007) não definiram condições ótimas para a germinação e desenvolvimento normal das plântulas.

Uma das causas sugeridas para a baixa porcentagem de germinação e o estabelecimento lento de plântulas seria a possível impermeabilidade do

'Programa de Pós-graduação em Fitotecnia, Universidade Federal do Rio Grande do Sul (UFRGS), 91540-000, Porto Alegre, RS, Brasil. E-mail: csfior@ufrgs.br. Autor para correspondência.

"Jardim Botânico, Fundação Zoobotânica do Rio Grande do Sul, Porto Alegre, RS, Brasil.

"IIFundação Estadual de Pesquisa Agropecuária, Porto Alegre, RS, Brasil.

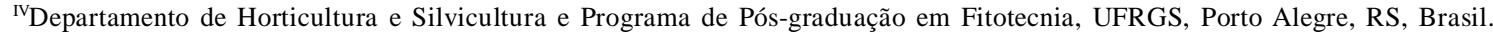


endocarpo (GEYMONAT \& ROCHA, 2009). No entanto, sua remoção influencia muito pouco a taxa de germinação (FIOR et al., 2004).

Não foram encontrados trabalhos abordando a possível interferência de tecidos da semente na germinação e no desenvolvimento do embrião de B. capitata. Por isso, foram conduzidos experimentos com o objetivo de identificar métodos para superação da dormência de sementes de $\boldsymbol{B}$. capitata estabelecidas in vitro e em germinador.

Foram coletados frutos maduros de cinco procedências (acessos), sendo quatro do Rio Grande do Sul [Encruzilhada do Sul (ES), Santa Maria (SM), Santa Vitória do Palmar (SV) e Chuí (CH)] e uma de Minas Gerais (Lontras) (MG). Logo após a coleta, os frutos foram despolpados manualmente e os diásporos lavados em água corrente e secos à sombra por $48 \mathrm{~h}$ (Figura 1A). Em seguida, foram acondicionados em embalagem de papel semi-craft com a borda dobrada e grampeada. Os diásporos dos acessos $\mathrm{SM}, \mathrm{SV}, \mathrm{CH}$ e MG permaneceram armazenados sob condições ambientais de laboratório por até 30 dias, enquanto os diásporos do acesso ES permaneceram em câmara seca com temperatura e umidade relativa do ar constantes em $17^{\circ} \mathrm{C} \mathrm{e} 45 \%$, por um ano. Embora com diferente tempo e condição de armazenamento, optou-se pela utilização do acesso ES, a fim de testar a eficiência do método de superação de dormência, mesmo com materiais heterogêneos.

O isolamento das sementes (Figura 1B) foi viabilizado pela quebra do endocarpo através de pressão mecânica gradual, em torno de bancada, de forma a romper o endocarpo mantendo as sementes íntegras, as quais foram desinfestadas por meio de imersão por um minuto em etanol $70 \%$, seguida de 20 minutos em hipoclorito de sódio a $2 \%$ de i.a., seguido de tríplice lavagem por 15 segundos em água destilada esterilizada, sob fluxo de ar laminar estéril.

No primeiro experimento, sementes dos acessos ES e MG foram distribuídas em três tratamentos: sementes íntegras - sem escarificação (SE) (Figura 1C); sementes com corte no opérculo da cavidade embrionária, de forma a exibir parte do botão germinativo por uma abertura parcial (AP) e sementes com abertura total (AT) da cavidade embrionária, de maneira a eliminar qualquer barreira mecânica ao embrião (Figura 1D). Após esse procedimento, as sementes foram estabelecidas sobre meio de cultivo MURASHIGE \& SKOOG (1962), com 3\% de sacarose, pH 5,8, gelificado com 0,8\% de ágar, em frascos de volume de $200 \mathrm{~mL}$, contendo $30 \mathrm{~mL}$ de meio. Em seguida, o material permaneceu em sala climatizada, com temperatura de $25 \pm 2^{\circ} \mathrm{C}$. O delineamento experimental foi em blocos casualizados, sendo dois blocos (acessos) e três tratamentos, com quatro subamostras de 10 sementes. Cada frasco foi considerado uma repetição. As avaliações ocorreram a cada 3 ou 4 dias até o $90^{\circ}$ dia.

No segundo experimento, sementes dos acessos SM, SV, CH e ES foram submetidas à abertura total a fim de verificar a eficiência desse tratamento na germinação e formação de plântulas fora do ambiente in vitro. Como unidades experimentais, foram utilizadas caixas de polietileno, tipo gerbox, preenchidas com $150 \mathrm{~mL}$ de areia média esterilizada, pré-umedecida com água destilada a $60 \%$ da capacidade de retenção de água da areia (BRASIL, 2009). Em cada caixa, foram estabelecidas 25 sementes sobre a areia e avaliadas a cada três ou quatro dias, por 150 dias. O ambiente utilizado foi um germinador tipo mangelsdorf a $25^{\circ} \mathrm{Ce}$ luz constante com intensidade luminosa de 200 Lux (lâmpadas fluorescentes tubulares de $32 \mathrm{~W}$ ). O delineamento utilizado foi inteiramente casualizado, com quatro subamostras de 25 sementes por tratamento.

Ao final das avaliações, em cada experimento, foram calculados: percentual de germinação $(\% \mathrm{G})$, plântulas formadas $(\% \mathrm{Pl})$, tempo médio de germinação (TMG) e formação das plântulas (TMP) (determinado segundo SILVA \& NAKAGAWA (1995), índice de velocidade de germinação (IVG) e formação de plântulas (IVP) com base na soma do número de sementes germinadas ou plântulas formadas em cada avaliação, dividido pelo respectivo tempo, dividindo-se o resultado final pelo número total de sementes germinadas ou plântulas formadas em cada repetição, segundo a fórmula de SILVA \& NAKAGAWA (1995), modificada conforme sugestão de SANTANA \& RANAL (2004).

Os dados de ambos os testes foram submetidos à análise de variância paramétrica e as médias foram comparadas pelo teste LSD (Fisher's Least Significant Difference Test) a 5\%.

No primeiro experimento, a abertura da cavidade embrionária facilitou significativamente a germinação, tanto com abertura parcial quanto total $(\mathrm{P}<0,01)$. No tratamento com abertura parcial, observou-se germinação a partir do segundo dia após o estabelecimento. As percentagens de germinação das sementes não escarificadas foram inferiores a $10 \%$, independentemente do acesso. A abertura parcial não foi suficiente para a máxima germinação, alcançando entre 15 e $35 \%$, enquanto a abertura total permitiu percentagens acima de $90 \%$ em um tempo médio de germinação inferior (10 dias) e índice de velocidade de germinação superior aos demais tratamentos $(\mathrm{P}<0,01)$. Também com a abertura total, houve elevada formação de plântulas (\%PI/G=92\%), com tempo médio de 29 dias. 

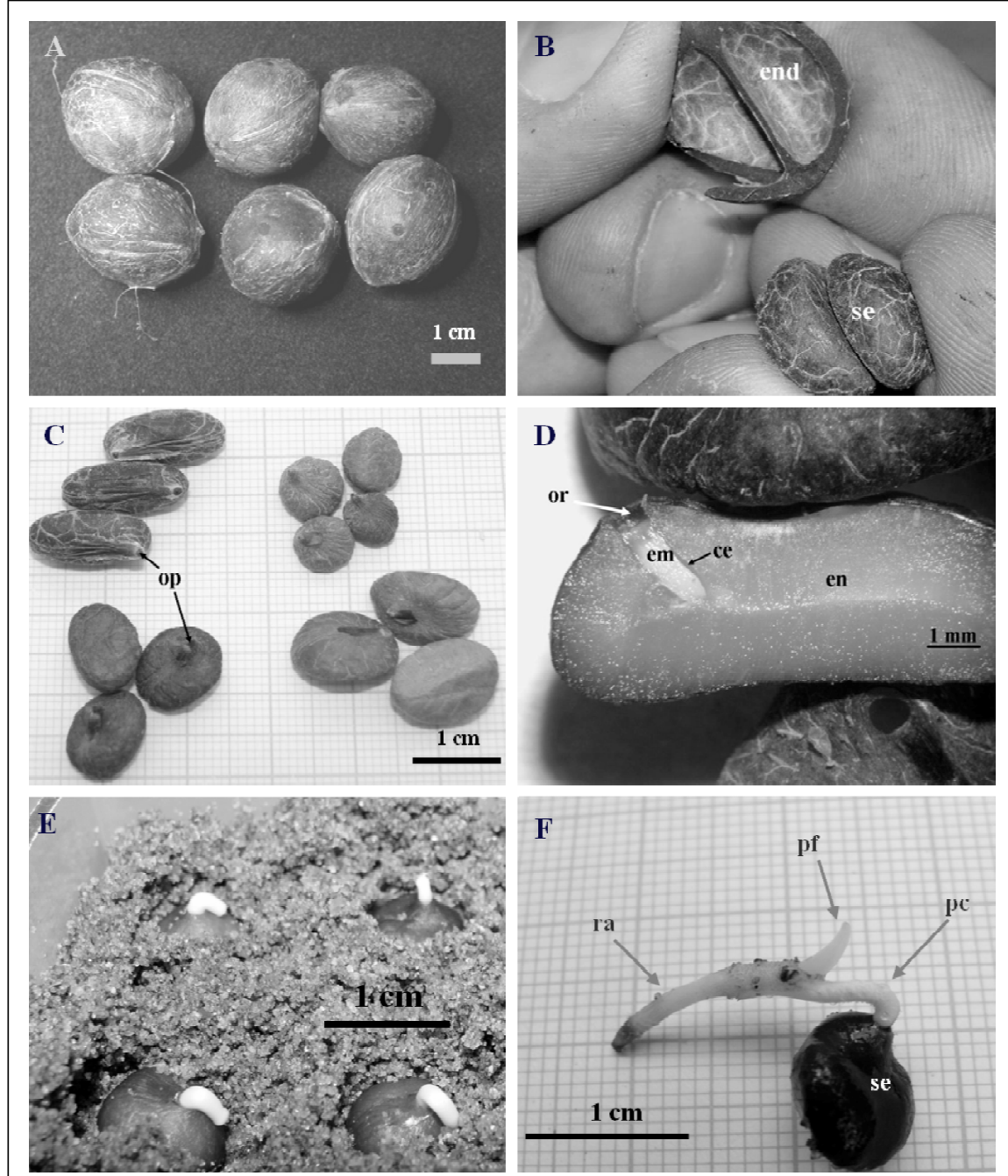

Figura 1 - Aspectos morfológicos de diásporos e sementes e germinação de Butia capitata. A: diásporos; B: sementes removidas dos endocarpos (end = endocarpo, se $=$ semente); C: sementes de quatro acessos (op = opérculo da cavidade embrionária); D: corte longitudinal de uma semente $($ en $=$ endosperma, ce $=$ cavidade embrionária, em $=$ embrião, or = cavidade embrionária com opérculo totalmente removido); E: sementes em germinação e F: plântula completa ( $\mathrm{se}=$ semente, $\mathrm{pc}=$ pecíolo cotiledonar, pf $=$ primeira folha, $\mathrm{ra}=$ raiz).

Apesar de os acessos representarem populações geograficamente distantes, os resultados foram semelhantes, com diferença apenas no tempo médio de formação das plântulas e índice de formação de plântulas ( $\mathrm{P}<0,01$ para ambas as variáveis), sendo o acesso MG com menor tempo médio de formação das plântulas e maior índice de formação de plântulas. Possivelmente, essa diferença esteja relacionada aos distintos genótipos representados pelos acessos, ou ainda devido à diferença entre os tempos e ambientes de armazenamento dos diásporos de cada acesso.

No segundo experimento, não houve diferença no percentual de germinação (média de $90 \%$ e $\mathrm{P}=0,14$ ), bem como do número de plântulas formadas em relação às sementes germinadas (média de $67 \%$ e $\mathrm{P}=0,07)$. Este percentual de germinação foi muito semelhante ao resultado da germinação in vitro, confirmando que a abertura total também foi eficiente em ambiente in vivo.

Diferença significativa foi observada entre acessos para o tempo médio e índice de velocidade de germinação ( $\mathrm{P}<0,01$ para ambas as variáveis), bem como para o percentual de plântulas formadas $(\mathrm{P}=0,02)$ e o respectivo IVP $(\mathrm{P}<0,01)$. Essas variáveis estão relacionadas ao vigor das sementes, sugerindo, portanto, maior vigor dos acessos $\mathrm{SV}$ e $\mathrm{CH}$. 
A retirada do opérculo da cavidade embrionária foi eficiente como tratamento de superação de dormência de sementes de $\boldsymbol{B}$. capitata, em ambos os testes, permitindo um percentual médio de germinação de $90 \%$.

Os resultados sugerem que a dormência das sementes dessa espécie não está relacionada ao embrião, mas sim à barreira mecânica imposta pelos tecidos da semente, o que dificulta o desenvolvimento do embrião na fase de germinação, caracterizando-se, portanto, como dormência exógena mecânica (BASKIN \& BASKIN, 1998).

Efeitos positivos da exposição de sementes de B. capitata a temperaturas altas (próximas a $40^{\circ} \mathrm{C}$ ) foram observados por CARPENTER (1988) e SCHLINDWEIN et al. (2007), os quais obtiveram elevados percentuais de germinação in vivo. Entretanto, CARPENTER (1988) e FIOR et al. (2004) obtiveram entre 74 e $100 \%$ de germinação de embriões in vitro, em meio de cultivo sem fitorreguladores, sob temperatura de $25^{\circ} \mathrm{C}$. Esses resultados sugerem que a temperatura elevada não é determinante para o desenvolvimento do embrião durante a germinação. Da mesma forma, os resultados do presente trabalho confirmam essa hipótese, pois os embriões das sementes recém-colhidas estavam aptos a germinar após a remoção do opérculo, tanto in vitro quanto in vivo, sem tratamento térmico.

Conclui-se que a abertura da cavidade embrionária das sementes de $\boldsymbol{B}$. capitata permitiu a superação da dormência, tanto em semeadura in vitro como in vivo, o que sugere que a dormência das sementes dessa espécie é exógena mecânica.

\section{AGRADECIMENTOS}

Ao Professor Bruno Francisco Sant'Anna dos Santos e sua equipe (UFMG), à Marta Coutinho da Silva (Fazenda Cordão - Santa Vitória do Palmar), a Frederico Karam (Summo Solo - Pelotas, RS), à Marina Silveira Gomes (Acadêmica em Ciências Biológicas, PUCRS), a Gilson Schlindwein e Adilson
Tonietto (FEPAGRO - Porto Alegre, RS) e a Cláudio Dutra Ávila (Santa Maria, RS).

\section{REFERÊNCIAS}

BASKIN, C.C.; BASKIN, J.M. Seeds: ecology, biogeography and evolution of dormancy and germination. San Diego: Academic, 1998. 666p.

BRASIL - Ministério da Agricultura, Pecuária e Abastecimento. Regras para análise de sementes. Brasília: Mapa/ACS, 2009. $399 \mathrm{p}$.

CARPENTER, W.J. Seed after-ripening and temperature influence in Butia capitata germination. HortScience, Alexandria, v.23, n.4, p.702-703, 1988.

FIOR, C.S. et al. Estudos da germinação in vivo e in vitro de Butia capitata (Martius) Beccari (Arecaceae). In: CONGRESSO NACIONAL DE BOTÂNICA, 55., 2004, Viçosa, MG. Palestras e Mesas Redondas... Viçosa: Universidade Federal de Viçosa, 2004. CD Rom.

GEYMONAT, G.; ROCHA, N. M'botiá. Ecosistema único en el mundo. Castillos: Casa Ambiental, 2009. 405p.

MURASHIGE, T.; SKOOG, F. A revised medium for rapid growth and bioassays with tobacco tissue cultures. Physiologia Plantarum, Köpenhagen, v.15, n.3, p.473-497, 1962.

ROBINSON, M.L. Cultivated palm seed germination. Reno: Cooperative Extension Bulletin. University of Nevada. Disponível em: <http://www.unce.unr.edu/publications/files/ho/ 2002/sp0209.pdf>. Online. Acesso em: 01 jun. 2010.

SANTANA, D.G.; RANAL, M.A. Análise da germinação um enfoque estatístico. Brasília: Universidade de Brasília, 2004. 248p.

SCHLINDWEIN, G. et al. Influência de regimes de temperatura e da secagem sobre germinação de diásporos de Butia capitata (Becc.). In: CONGRESO NACIONAL DE HORTIFRUTICULTURA, 11.; CONGRESO DE PROMOCIÓN DEL CONSUMO DE FRUTAS Y VERDURAS, 3., 2007, Montevideo. Resumos... Montevideo: Sociedad Uruguaya de Hortifruticultura, 2007. 1 CD-ROM.

SILVA, J.B.C.; NAKAGAWA, J. Estudos de fórmulas para cálculo de germinação. Informativo ABRATES, Londrina, v.5, n.1, p.62-73, 1995.

TONIETTO, A. et al. Usos e potencialidades do butiazeiro. Porto Alegre: FEPAGRO, 2009. 28p. (Circular Técnica, 26). 